\title{
Effect of Salinity Stress on Glutathione $-S$-Transferases (GSTs) of Maize
}

\author{
R. N. Remme ${ }^{1 *}$, N. A. $\operatorname{Ivy}^{2}$, M. A. K. Mian ${ }^{3}$, M. Rohman ${ }^{4}$ \\ $I^{*}$ (Lecturer, Agrotechnology Discipline, Khulna University, Bangladesh) \\ ${ }_{2}^{2}$ Associate professor, Genetics and Plant Breeding, Bangabandhu Sheikh Mujibur Rahman Agricultural \\ University, Bangladesh) \\ ${ }^{3}$ (Professor, Genetics and Plant Breeding, Bangabandhu Sheikh Mujibur Rahman Agricultural University, \\ Bangladesh) \\ ${ }^{4}$ (Senior Scientific Officer, Plant Breeding Division, Bangladesh Agricultural Research Institute, Bangladesh)
}

\begin{abstract}
The present study was undertaken to explore the responses of maize GST to salinity. GST activities were found to induce with the increasing of salinity levels and duration of stress. At 3 day, 5 day and 7 day stress most of all the salinity concentration (4 dS/m, $8 \mathrm{dS} / \mathrm{m}$ and $12 \mathrm{dS} / \mathrm{m}$ ) increased the GST activities over control. However $16 \mathrm{dS} / \mathrm{m}$ salinity decreased the activity over control. In foliar application of proline GST activities were increased gradually over control and $\mathrm{NaCl}$ treatment at 3 day, 5 day and 7 day stress in all the salinity level. In betaine application at $4 \mathrm{dS} / \mathrm{m}, 8 \mathrm{dS} / \mathrm{m}, 12 \mathrm{dS} / \mathrm{m}$ and $16 \mathrm{dS} / \mathrm{m}$ salinity also increased GST activity were gradually over control at 3 day, 5 day and 7 day stress. It also increases the GST activity during the stress period over $\mathrm{NaCl}$ stress in all the salinity levels, except $12 \mathrm{dS} / \mathrm{m}$ and $16 \mathrm{dS} / \mathrm{m}$ salinity at 3 day stress. When both proline and betaine applied together in stressed seedlings at $4 \mathrm{dS} / \mathrm{m}, 8 \mathrm{dS} / \mathrm{m}, 12 \mathrm{dS} / \mathrm{m}$ and $16 \mathrm{dS} / \mathrm{m}$ salinity increased the GST activity at 3 day, 5 day and 7 day stress over control. Though the combination of 15 $m M$ proline and betaine decreased the activities at 3 day and 7 day stress at $4 \mathrm{dS} / \mathrm{m}, 8 \mathrm{dS} / \mathrm{m}$ and $12 \mathrm{dS} / \mathrm{m}$ at 3 day stress GST activity increased at other salinity stress in different stress period. To examine the detoxification role of maize GST, concentration of MDA (peroxident product of poly unsaturated fatty acid) in the stressed maize seedlings was studied. In all the salinity levels, MDA contents increased over control. Supplementation of proline and betaine reduced the concentrations of MDA over salinity stresses. The simultaneous increased GST activities and lower MDA concentration suggested the detoxification role of maize GST on cytotoxic MDA.
\end{abstract}

Keywords: Glutathione-S-transferases, Maize, $\mathrm{NaCl}$, Melondialdehide

\section{Introduction}

Abiotic stresses, such as drought, salinity, cold, high temperature, chemical toxicity, high light intensity and oxidative stresses lead to a series of morphological, physiological, biochemical and molecular changes that adversely affect plant growth and productivity and reduce crop yields by more than $50 \%$ worldwide (Wang et al., 2002). Different abiotic stresses including salinity trigger in plants oxidative stress, generating the formation of reactive oxygen species (ROS). These species are partially reduced or activated derivatives of oxygen, comprising both free radical $\left(\mathrm{O}_{2}^{-},{ }^{1} \mathrm{O}_{2} \mathrm{OH}, \mathrm{OH}_{2}\right)$ and non-radical $\left(\mathrm{H}_{2} \mathrm{O}_{2}\right)$ forms, leading to cellular damage, metabolic disorders and senescence processes, structural and functional loss of cell organelles, and eventually lead to death (Blokhina et al., 2003). To protect themselves against toxic oxygen intermediates and xenobiotics, various defense systems evolved within the plant that includes antioxidant enzymes. Plants possess an impressive array of antioxidant enzymes of which glutathione $S$-transferases are an important group. GSTs are a family of enzymes which catalyze the configuration of reduced GSH (tripeptide of $\gamma$-Glu-Cys-Gly) to a variety of electrophilic compounds to direct them to specific sites both intra- and extra-cellularly. GSTs are proposed to afford protection under various stress conditions by detoxifying endogenous plant toxins that accumulate as a consequence of increased oxidative stress (Marrs, 1996). In plant, GSTs, originally characterized by their ability to modify xenobiotics covalently by glutathionation, are rapidly induced by their substrates, particularly plant herbicides (Dean et al., 2005). There has been increasing evidence indicating that GSTs may be implicated many other physiological processes. These include, stress response (Anderson and Davis, 2004), catalytic mechanism (Atkins et al., 2003), protection of tissue from oxidative damage, lipid per oxidation (Yang et al., 2001), ligandin functions (Axarli et al., 2004), and protection of tissue from heavy metals (Marrs, 1996). After discovering of GSTs in 1970 in maize, they have been extensively studied for detoxification of xenobiotics, detoxification of endogenous cytotoxic substances (Marrs, 1996; Jepson et al., 1997; Muller et al., 2000; Dixon et al., 2002; Rohman et al., 2009). Though GSTs have been reported to have important roles under different biotic and abiotic stress environments, such information on maize GSTs are poorly available except drought; chilling tolerance (Abenavoli et al., 2001). However, information on responses of maize GSTs to salinity responses is very limited. 
There are evident that under stress condition, osmoprotectants like betaine, proline, glycine, jaesmonin acid, NO etc. are produced and among which proline and betaine are more common (Hossain and Fujita, 2010). It is reported that betaine and proline synthesis in maize under abiotic stress with protective roles (Ashraf and Foolad, 2007) and able to express antioxidant activity (Hossain and Fujita, 2010; Hoque et al., 2007a). Considering all, this study was under taken to investigate the responses of maize GST to salinity.

\subsection{Experimental site}

\section{Materials and Methods}

This study was carried out in the Molecular Breeding Laboratory of Bangladesh Agricultural Research Institute (BARI), Joydebpur, Gazipur during the period from April, 2011 to August, 2012.

\subsection{Plant materials}

Seedlings of maize (BARI Hybrid Maize 7) were used as plant material.

\subsection{Chemicals}

All of the chemicals except Hydroxylapaptite, $\mathrm{NaCl}$ (Merck, Germany) were used manufactured from Sigma-Aldrich, USA.

\subsection{Stress treatments}

Maize seedlings were grown in plastic pots. Five days old seedlings were subjected for stress implementation. Salinity levels $(4,8$ and $12 \mathrm{dS} / \mathrm{m})$ were maintained by adding $\mathrm{NaCl}$ and water. A control treatment (with adding $\mathrm{NaCl}$ ) was also growing under same condition. In $\mathrm{NaCl}$ stressed seedlings $15 \mathrm{mM}$ proline and $15 \mathrm{mM}$ betaine were applied as foliar spray twice daily. Digital EC meter was used to measured level of salinity, and the level was expressed at field capacity.

\subsection{Preparation of soluble protein}

To assay the activity level of GST in maize seedlings five gram of sample was homogenized in an equal volume of $50 \mathrm{mM}$ potassium phosphate buffer ( $\mathrm{pH} 7.0)$ containing $100 \mathrm{mM} \mathrm{KCl}, 1 \%(\mathrm{w} / \mathrm{v})$ ascorbate and $10 \%(\mathrm{w} / \mathrm{v})$ glycerol with mortar and pestle. The homogenates were centrifuged at $11,500 \times \mathrm{g}$ for $10 \mathrm{~min}$ and the supernatant was used as a soluble protein solutions.

\subsection{Measurement of lipid peroxidation}

The level of lipid peroxidation was measured by estimating MDA, a decomposition product of the peroxidized polyunsaturated fatty acid component of the membrane lipid, using thiobarbituric acid (TBA) as the reactive material following the method of Heath and Packer (1968) with slight modifications. The seedlings (2.5 g) were homogenized in $15 \mathrm{ml} \mathrm{5 \% (w/v)} \mathrm{trichloroacetic} \mathrm{acid} \mathrm{(TCA)} \mathrm{and} \mathrm{the} \mathrm{homogenate} \mathrm{was} \mathrm{centrifuged} \mathrm{at}$ $11,500 \mathrm{rpm}$ for $10 \mathrm{~min}$. One $\mathrm{ml}$ supernatant was mixed with $4 \mathrm{ml}$ of TBA reagent $(0.5 \%$ of TBA in $20 \%$ TCA). The reaction mixture was heated at $95^{\circ} \mathrm{C}$ for $30 \mathrm{~min}$ in a water bath and then quickly cooled in an ice bath and centrifuged at $11,500 \mathrm{~g}$ for $15 \mathrm{~min}$. The absorbance of the colored supernatant was measured at $532 \mathrm{~nm}$ and was corrected for non-specific absorbance at $600 \mathrm{~nm}$. The concentration of MDA was calculated by using the extinction coefficient of $155 \mathrm{mM}^{-1} \mathrm{~cm}^{-1}$ and expressed as nmol of MDA g ${ }^{-1}$ fresh weight.

\subsection{Data analysis}

Data generated from this study were analyzed by MSTAT software where need. The graphs were prepared in MS Excel, 2007.

\section{Results and Discussion}

Since proline and betaine, the most common osmolytes synthesis under abiotic stresses with protective roles through over expression of antioxidant machinery including GST, to examine the responses of maize GST was tested under saline stress supplemented with proline and betaine. The activities changes in different level under different treatments. The activity also changed differently over duration of stresses.

\subsection{Changes in GST activities at $4 \mathrm{dS} / \mathrm{m}$ salinity}

At $4 \mathrm{dS} / \mathrm{m}$ salinity, GST activity increased over control but it was statistically insignificant at 3 day stress. It increased the activity $10.54 \%$ over control from 199.11 to $220.10 \mathrm{nmol} / \mathrm{min} / \mathrm{mg}$ protein (Fig. 1). In foliar application of proline and betaine at $15 \mathrm{mM}$ concentration the activity increased significantly by proline and betaine individually over control. However, the combined application of proline and betaine under this level of salinity the activity slightly increased over control, but slightly lower than the activity level under $4 \mathrm{dS} / \mathrm{m}$ salinity. The activity levels increased in proline and betaine supplemented $\mathrm{NaCl}$ treated maize seedlings were 
$19.58 \%$ and $18.06 \%$, respectively over control and 8.18 and $6.80 \%$, respectively over $\mathrm{NaCl}$ (Table 1 ) at this stage.

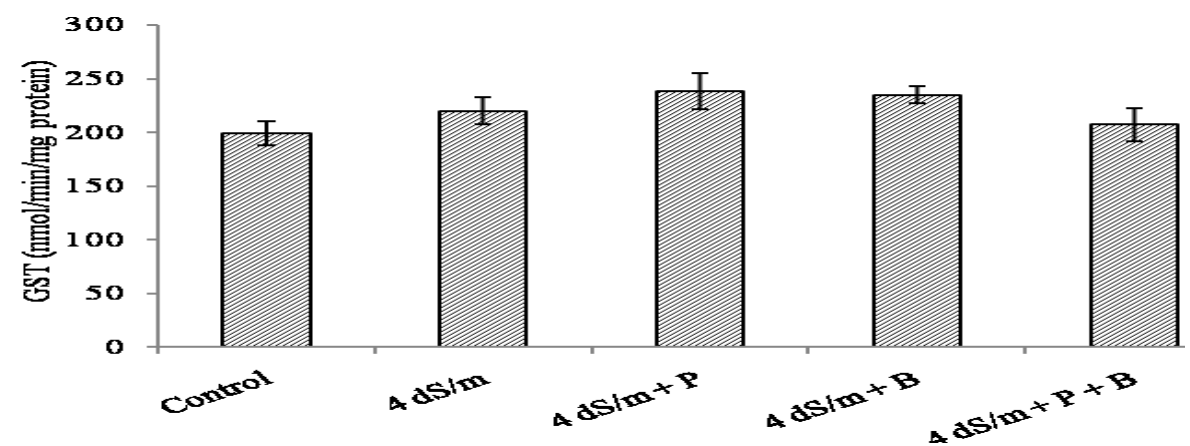

Fig. 1. Changes in the activity of GST in maize seedlings under $4 \mathrm{dS} / \mathrm{m}$ salinity stress supplemented with proline and betaine at 3 day stress.

At 5 day of stress under $4 \mathrm{dS} / \mathrm{m}$ salinity, the activities of GST increased more than 3 day stress (Fig. 2 and Table 1). At this stage, the activity increased $16.33 \%$ to $230.98 \% \mathrm{nmol} / \mathrm{min} / \mathrm{mg}$ protein over control which was statistically significant. The foliar application of proline and betaine increased the activities over control and $4 \mathrm{dS} / \mathrm{m}$ salinity. However, the seedlings treated with both proline and betaine slightly $(6.38 \%)$ increased the activity over $\mathrm{NaCl}$ treatment. Supplementation of proline and betaine increased activity by $53.66 \%$ and $39.77 \%$, respectively over control, and $32.09 \%$ and $20.15 \%$, respectively over $\mathrm{NaCl}$ treatment.

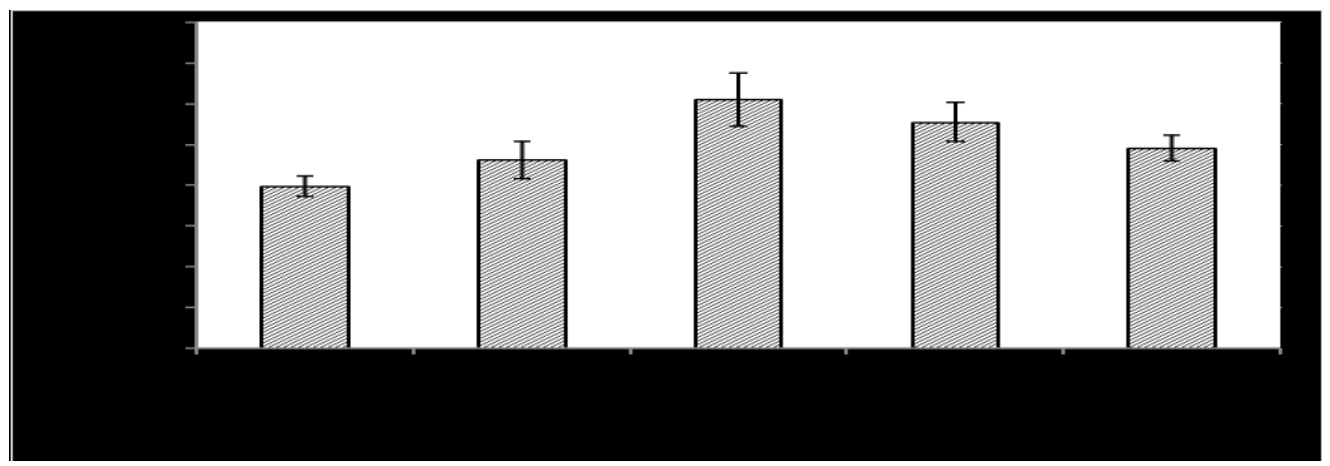

Fig. 2. Changes in the activity of GST in maize seedlings under $4 \mathrm{dS} / \mathrm{m}$ salinity stress supplemented with proline and betaine at 5 day stress

At 7 day of stress under $4 \mathrm{dS} / \mathrm{m}$ salinity, the activities of GST also increased more than 5 day stress (Fig. 2 and Table 1) and the activity was found to increase significantly over control at 7 day stress over control. The activity increased $34.03 \%$ to $270.20 \mathrm{nmol} / \mathrm{min} / \mathrm{mg}$ protein from $201.59 \mathrm{nmol} / \mathrm{min} / \mathrm{mg}$ protein. The sole application of proline and betaine increased the activities significantly over control and $4 \mathrm{dS} / \mathrm{m}$ salinity at this stage. The exogenous application of proline and betaine increased activity by $58.99 \%$ and $51.40 \%$, respectively over control, and $18.62 \%$ and $12.95 \%$, respectively over $\mathrm{NaCl}$ treatment. However, though the combined application proline and betaine increased the activity $(28.48 \%)$, it decreased $4.15 \%$ activity over $\mathrm{NaCl}$ treatment in maize seedlings.

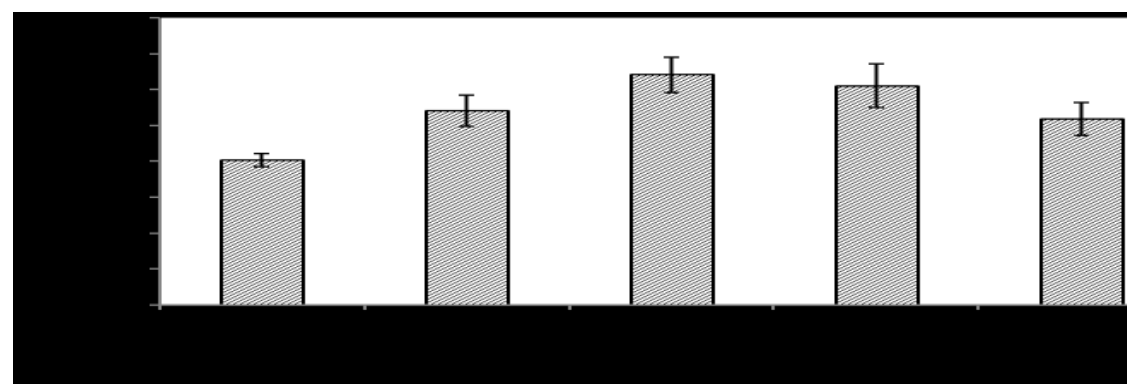

Fig. 3. Changes in the activity of GST in maize seedlings under $4 \mathrm{dS} / \mathrm{m}$ salinity stress supplemented with proline and betaine at 7 day stress

Table 1. Percentage of activity changed over control and $4 \mathrm{dS} / \mathrm{m} \mathrm{NaCl}$ treatment in maize seedlings supplemented with proline (P) and betaine (B) 
Effect of Salinity Stress on Glutathione-S-Transferases (GSTS) of Maize

\begin{tabular}{l|l|l|l|l|l|l}
\hline \multirow{2}{*}{ Treatment } & \multicolumn{4}{|c|}{ \% activity increased over control } & \multicolumn{3}{c}{ \% activity increased over NaCl } \\
\cline { 2 - 7 } & $\mathbf{3 ~ d a y}$ & $\mathbf{5 ~ d a y}$ & $\mathbf{7 ~ d a y}$ & $\mathbf{3}$ day & $\mathbf{5}$ day & $\mathbf{7}$ day \\
\hline $4 \mathrm{dS} / \mathrm{m}$ & 10.54 & 16.33 & 34.03 & - & - & - \\
$4 \mathrm{dS} / \mathrm{m}+\mathrm{P}$ & 19.58 & 53.66 & 58.99 & 8.18 & 32.09 & 18.62 \\
$4 \mathrm{dS} / \mathrm{m}+\mathrm{B}$ & 18.06 & 39.77 & 51.40 & 6.80 & 20.15 & 12.95 \\
$4 \mathrm{dS} / \mathrm{m}+\mathrm{P}+\mathrm{B}$ & 4.08 & 23.75 & 28.48 & -5.85 & 6.38 & -4.15 \\
\hline
\end{tabular}

\subsection{Changes in GST activities at $8 \mathrm{dS} / \mathrm{m}$ salinity}

At $8 \mathrm{dS} /$ salinity GST activities were found to be changed over duration of stress (Fig. 4 and Table 2). At this salinity level the activity increased $12.92 \%$ over control in 3 day stressed seedlings, however, at this stage; the increased level was not significantly higher than the control. Among the osmolytes, only in proline supplemented $\mathrm{NaCl}$ stressed seedlings, the activity significantly increased over control (27.85\%), but over $\mathrm{NaCl}$ it only increased $13.52 \%$ activity only (Table 2). Though betaine increased the activities by $16.71 \%$ and $3.61 \%$ over control and $\mathrm{NaCl}$ treated seedlings, in the combined application of the osmolites, the activity remained almost similar.

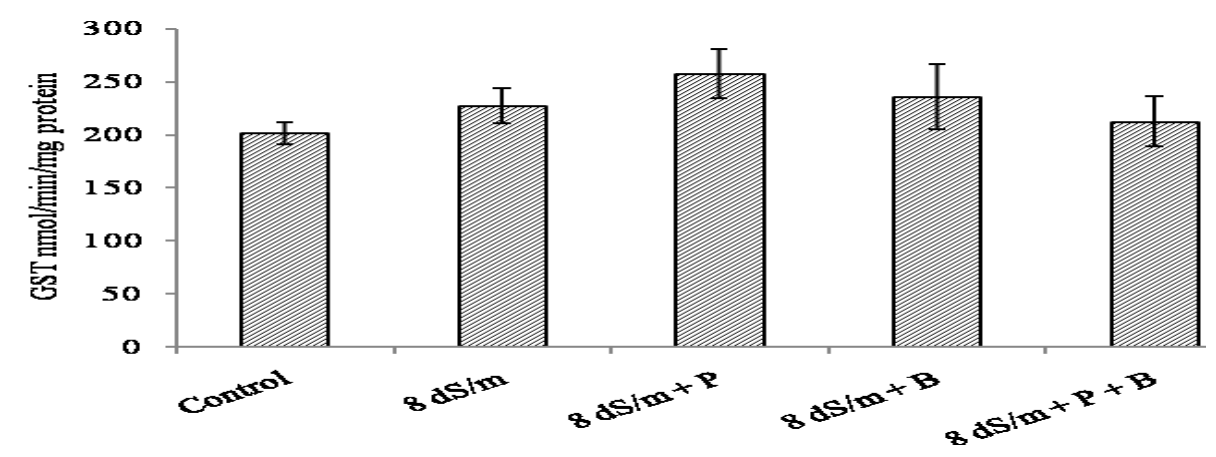

Fig. 4. Changes in the activity of GST in maize seedlings under $8 \mathrm{dS} / \mathrm{m}$ salinity stress supplemented with proline and betaine at 3 day stress

During the stress period, 5 day stress resulted in the highest induction of GST activity under $8 \mathrm{dS} / \mathrm{m}$ salinity (Fig. 5 and Table 2). At this stage, the $8 \mathrm{dS} / \mathrm{m}$ salinity increased $31.05 \%$ activity from 192.47 to 252.24 $\mathrm{nmol} / \mathrm{min} / \mathrm{mg}$ protein, which was statistically significantly higher than control. The foliar single spray of $15 \mathrm{mM}$ proline and betaine and their combined application increased the activity level increased significantly $(79.62 \%$, $46.78 \%$ and $31.48 \%$, respectively) over control under this salinity level. Interestingly, proline magnificently enhanced the activity of $8 \mathrm{dS} / \mathrm{m}$ from 270.70 to $315.20 \mathrm{nmol} / \mathrm{min} / \mathrm{mg}$ protein which increased 1.8 fold activities suggesting the protective role of GST through activating its activity by proline. Though the betaine increased the activity slightly over $\mathrm{NaCl}$, the activity level remained similar in combined application of proline and betaine at this stage.

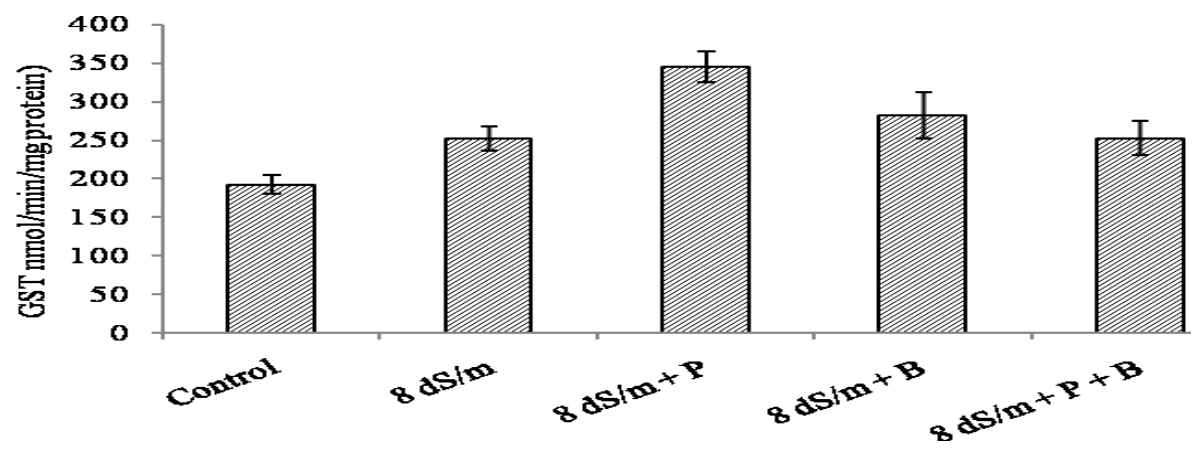

Fig. 5. Changes in the activity of GST in maize seedlings under $8 \mathrm{dS} / \mathrm{m}$ salinity stress supplemented with proline and betaine at 5 day stress

At 7 day of stress, the GST activities were observed to be decrease that the activities at 5 day stress in the osmolites supplemented seedlings; however, the $\mathrm{NaCl}$ slightly increased the activity (Table 2). From the figure 6 we found that the activity significantly increased (33.68\%) over control. At this stage, only proline could able to increase the activity significantly over control and $\mathrm{NaCl}$ treatment $(55.65 \%$ and $16.44 \%$, respectively). On the other hand, the activity in betaine supplemented seedlings did not able to increase the 
activity over $\mathrm{NaCl}$, where, the activity level by combined of the osmolites remains statistically similar to control (Fig. 6).

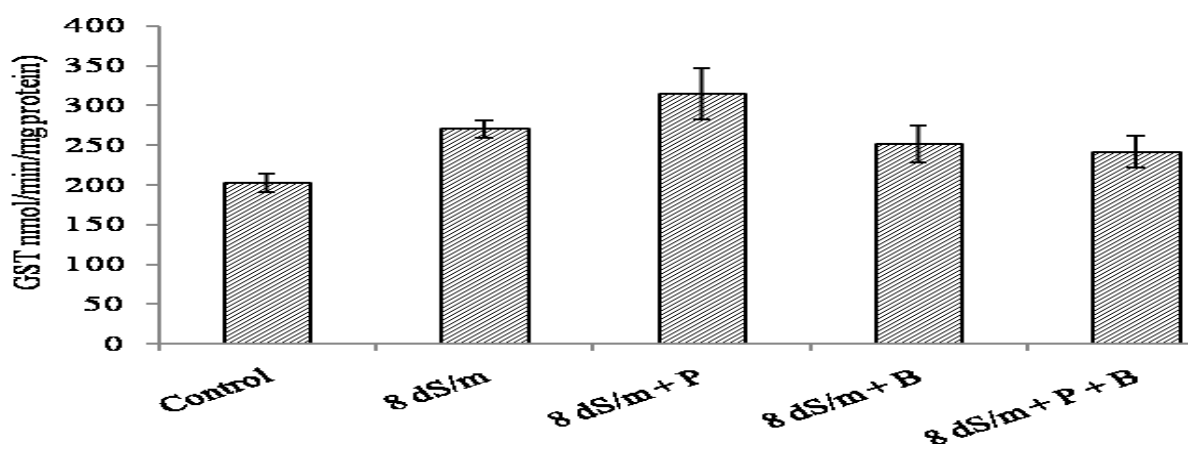

Fig. 6. Changes in the activity of GST in maize seedlings under $8 \mathrm{dS} / \mathrm{m}$ salinity stress supplemented with proline and betaine at 7 day stress

Table 2. Percentage of activity changed over control and $8 \mathrm{dS} / \mathrm{m} \mathrm{NaCl}$ treatment in maize seedlings supplemented with proline and betaine

\begin{tabular}{l|l|l|l|l|l|l}
\hline \multirow{2}{*}{ Treatment } & \multicolumn{3}{|c|}{ \% activity increased over control } & \multicolumn{3}{c}{ \% activity increased over NaCl } \\
\cline { 2 - 7 } & 3 day & 5 day & 7 day & 3 day & $\mathbf{5}$ day & 7 day \\
\hline $8 \mathrm{dS} / \mathrm{m}$ & 12.92 & 31.05 & 33.68 & - & - & - \\
$8 \mathrm{dS} / \mathrm{m}+\mathrm{P}$ & 27.85 & 79.62 & 55.65 & 13.52 & 37.06 & 16.44 \\
$8 \mathrm{dS} / \mathrm{m}+\mathrm{B}$ & 16.71 & 46.78 & 24.54 & 3.61 & 12.00 & -6.83 \\
$8 \mathrm{dS} / \mathrm{m}+\mathrm{P}+\mathrm{B}$ & 5.47 & 31.41 & 19.51 & -4.49 & 0.27 & -10.60 \\
\hline
\end{tabular}

\subsection{Changes in GST activities at $12 \mathrm{dS} / \mathrm{m}$ salinity}

At 3 day stress, $12 \mathrm{dS} / \mathrm{m}$ salinity increased the activity significantly over control (Fig. 7). It increased $21.74 \%$. The individual application of proline and betaine in $\mathrm{NaCl}$ induced salinity increased the activity significantly $(42.15 \%$ and $20.05 \%$, respectively), where GST activity increased significantly in only proline supplemented maize seedlings over $\mathrm{NaCl}$ treatment. It increased $16.94 \%$ activity. Though the application of both proline and betaine increased the activity slightly over untreated control, the activity levels were statistically similar.

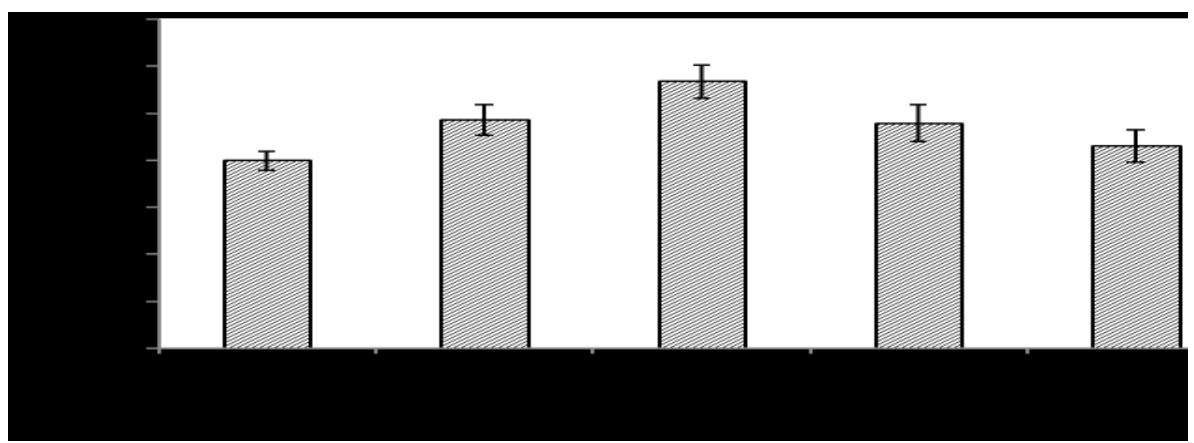

Fig. 7. Changes in the activity of GST in maize seedlings under $12 \mathrm{dS} / \mathrm{m}$ salinity stress supplemented with proline and betaine at 3 day stress

Though at 5 day stress at $12 \mathrm{dS} / \mathrm{m}$ salinity showed higher GST activities than 3 day stress, the activity levels were lower than those of 5 day stressed seedlings under $8 \mathrm{dS} / \mathrm{m}$ salinity (Fig. 8 and Table 3 ). All the treatments increased the activity significantly over control (Fig. 8). The $12 \mathrm{dS} / \mathrm{m}$ salinity increased $24.76 \%$ activity suggesting its inducibility under salinity stress. This activity was found to be further augmented in presence of $15 \mathrm{mM}$ proline, while, it increased the activity (23.87\%) significantly over $\mathrm{NaCl}$. 


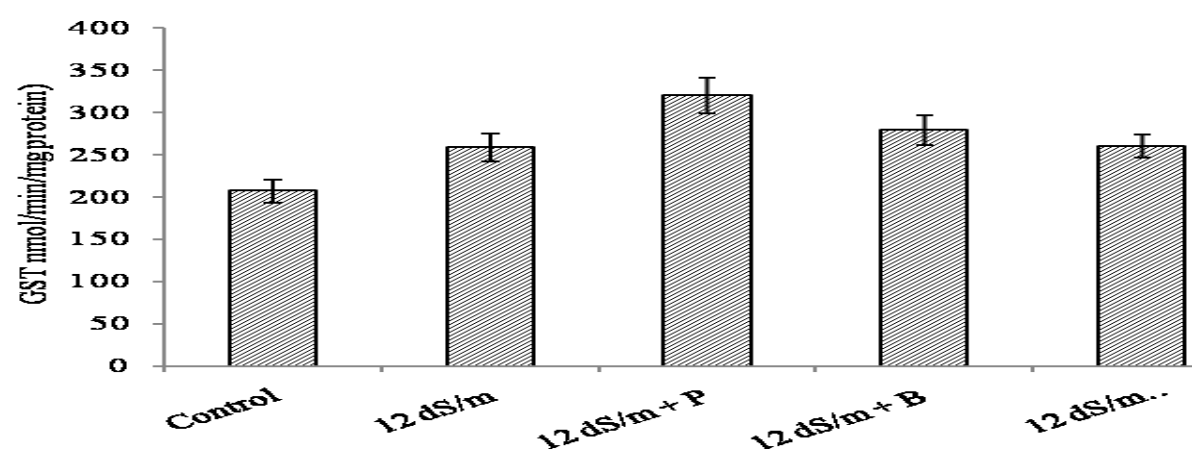

Fig. 8 Changes in the activity of GST in maize seedlings under $12 \mathrm{dS} / \mathrm{m}$ salinity stress supplemented with proline and betaine at 5 day stress

At 7 day stress, $12 \mathrm{dS} / \mathrm{m}$ salinity the GST activity was found to increase slightly (5.25\%) over control, but statistically insignificant (Fig. 9 and Table 3). Proline alone and in combination with betaine increased the activity over control $(38.71 \%$ and $24.32 \%$, respectively) and $\mathrm{NaCl}(31.80 \%$ and $18.12 \%$, respectively). The activity increased by betaine alone was significantly higher $(22.68 \%)$ than the untreated control.

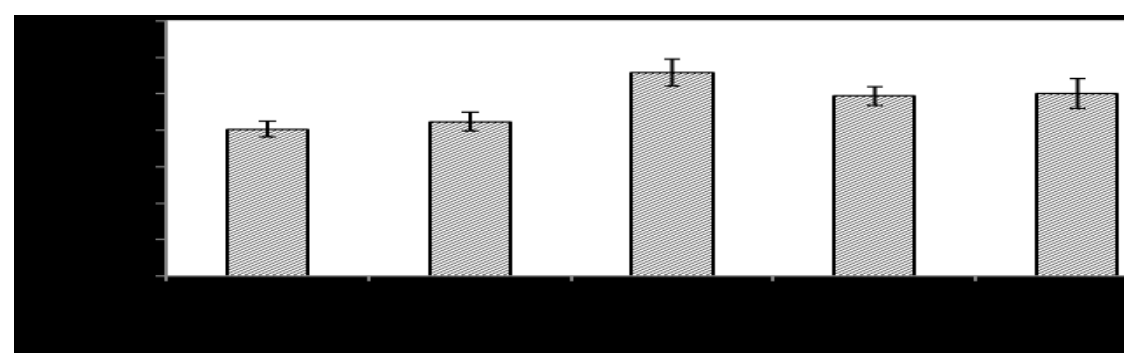

Fig. 9. Changes in the activity of GST in maize seedlings under $12 \mathrm{dS} / \mathrm{m}$ salinity stress supplemented with proline and betaine at 7 day stress

Table 3. Percentage of activity changed over control and $12 \mathrm{dS} / \mathrm{m} \mathrm{NaCl}$ treatment in maize seedlings supplemented with proline and betaine

\begin{tabular}{l|l|l|l|l|l|l}
\hline \multirow{2}{*}{ Treatment } & \multicolumn{2}{l|}{ \% activity increased over control } & \multicolumn{3}{c}{ \% activity increased over NaCl } \\
\cline { 2 - 7 } & 3 day & $\mathbf{5}$ day & $\mathbf{7}$ day & 3 day & $\mathbf{5}$ day & $\mathbf{7}$ day \\
\hline \multirow{2}{*}{$12 \mathrm{dS} / \mathrm{m}$} & 21.74 & 24.76 & 5.25 & & & \\
$12 \mathrm{dS} / \mathrm{m}+\mathrm{P}$ & 42.15 & 54.54 & 38.71 & 16.94 & 23.87 & 31.80 \\
$12 \mathrm{dS} / \mathrm{m}+\mathrm{B}$ & 20.05 & 34.75 & 22.68 & -1.39 & 8.01 & 16.57 \\
$12 \mathrm{dS} / \mathrm{m}+\mathrm{P}+\mathrm{B}$ & 7.88 & 25.51 & 24.32 & -11.38 & 0.60 & 18.12 \\
\hline
\end{tabular}

\subsection{Changes in GST activities at $16 \mathrm{dS} / \mathrm{m}$ salinity}

At 3 day stress under $16 \mathrm{dS} / \mathrm{m}$ salinity increased the activity (18.72\%) but it was statistically similar to the activity level of untreated control (Fig. 10 and Table 4). Though the application of proline at $15 \mathrm{mM}$ remained the activity slightly (10.40\%) under $16 \mathrm{dS} / \mathrm{m}$ salinity, it was insignificant over $\mathrm{NaCl}$. Therefore, at this stage, the lower rate of increased activity due to toxic effect of high salinity as well as the detrimental effect of ROS produced under salinity stress.

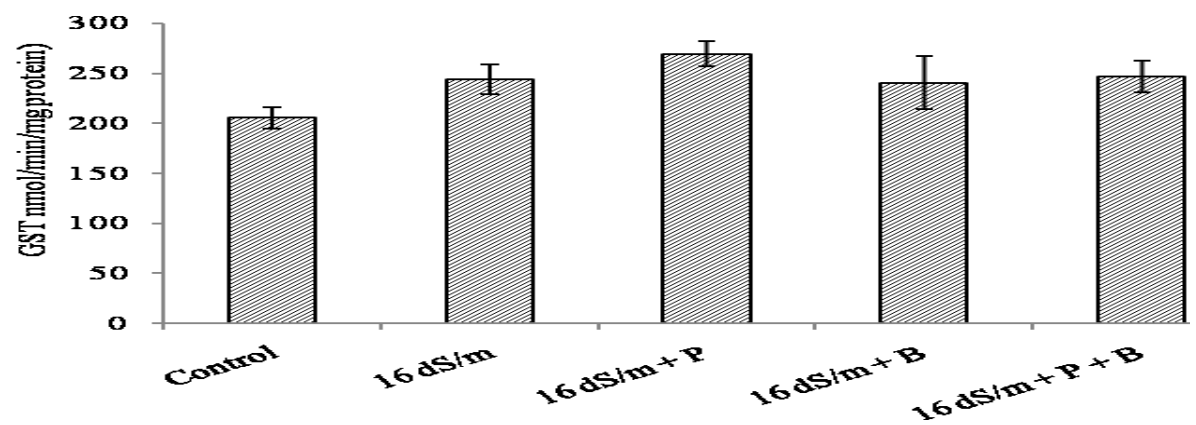

Fig. 10. Changes in the activity of GST in maize seedlings under $16 \mathrm{dS} / \mathrm{m}$ salinity stress supplemented with proline and betaine at 3 day stress 
At 5 day of stress, though all the treatment increased the activity significantly over control, the only application of proline maintained the activity significantly higher over $16 \mathrm{dS} / \mathrm{m}$ salinity (Fig. 11). This level of salinity increased $14.96 \%$ activity over control which was statistically similar to the activity levels under salinity with betaine and salinity with proline plus betaine (Table 4). Proline maintained the activities $51.07 \%$ and $31.41 \%$ higher over control and $16 \mathrm{dS} / \mathrm{m}$ salinity at this stage.

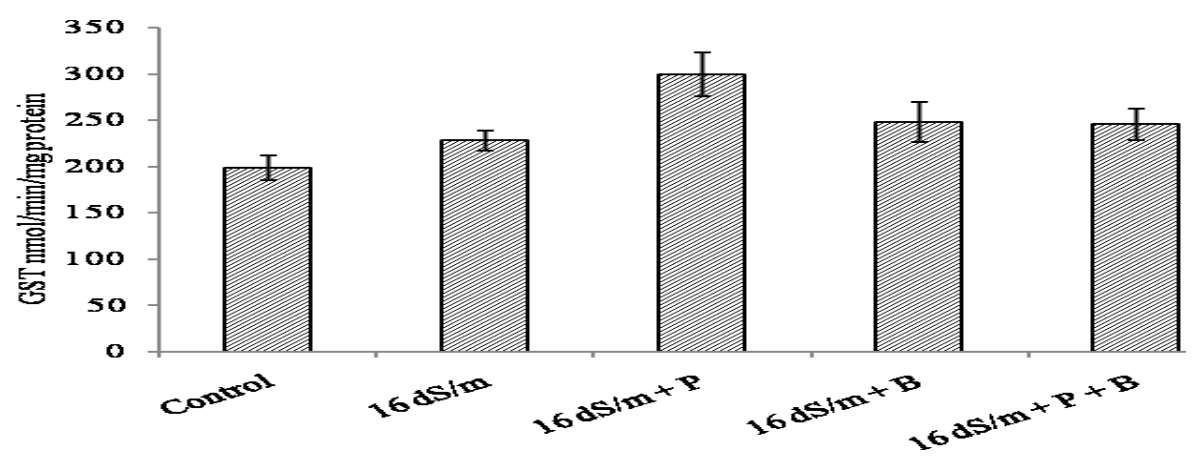

Fig. 11. Changes in the activity of GST in maize seedlings under $16 \mathrm{dS} / \mathrm{m}$ salinity stress supplemented with proline and betaine at 5 day stress

At 7 day stress the GST activity was found to be down-regulated over control at $16 \mathrm{dS} / \mathrm{m}$ salinity and both proline and betaine maintained the activities significantly higher over $\mathrm{NaCl}$. GST activities increased $24.77 \%$ and $58.97 \%$ over control and $\mathrm{NaCl}$, respectively in proline treated seedlings at this stage. Interestingly, at this high salinity stress betaine also maintained the activity higher over salinity stress alone (Fig. 12 and Table 4).

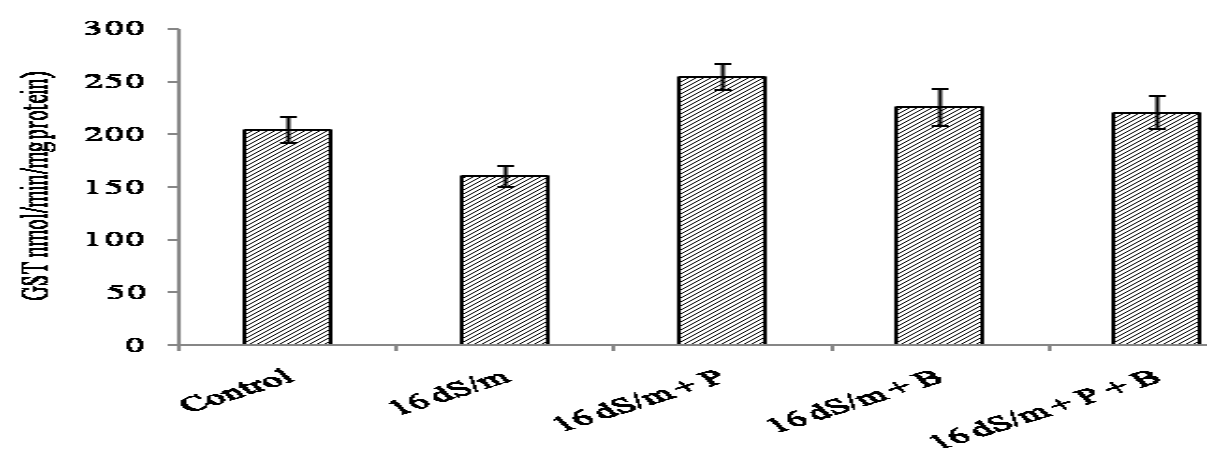

Fig. 12. Changes in the activity of GST in maize seedlings under $16 \mathrm{dS} / \mathrm{m}$ salinity stress supplemented with proline and betaine at 7 day stress

Table 4. Percentage of activity changed over control and $16 \mathrm{dS} / \mathrm{m} \mathrm{NaCl}$ treatment in maize seedlings supplemented with proline and betaine

\begin{tabular}{|c|c|c|c|c|c|c|}
\hline \multirow{2}{*}{ Treatment } & \multicolumn{3}{|c|}{$\%$ activity increased over control } & \multicolumn{3}{|c|}{$\%$ activity increased over $\mathrm{NaCl}$} \\
\hline & 3 day & 5 day & 7 day & 3 day & 5 day & 7 day \\
\hline $16 \mathrm{dS} / \mathrm{m}$ & 18.72 & 14.96 & -21.52 & & & \\
\hline $16 \mathrm{dS} / \mathrm{m}+\mathrm{P}$ & 31.06 & 51.07 & 24.77 & 10.40 & 31.41 & 58.97 \\
\hline $16 \mathrm{dS} / \mathrm{m}+\mathrm{B}$ & 16.97 & 25.04 & 10.65 & -1.47 & 8.76 & 40.98 \\
\hline $16 \mathrm{dS} / \mathrm{m}+\mathrm{P}+\mathrm{B}$ & 20.08 & 23.68 & 8.23 & 1.15 & 7.58 & 37.90 \\
\hline
\end{tabular}

In this study, the GST activities increased with increasing concentration of salinity and duration of stress (Fig. 1-12) which suggested that GST could be induced to eliminate the toxic lipid peroxidises and $\mathrm{H}_{2} \mathrm{O}_{2}$, as production of these compounds are common phenomenon under abiotic stresses including $\mathrm{NaCl}$ (Awasthi et al., 2003b; Yang et al., 2003; Alexios et al., 1999; Hossain and Fujita, 2010). Here GST could important role in protecting cells through antioxidant and detoxification activities. At higher concentration and at 7 day stress, the decreased GST activities might be due to loss of cellular membrane intrigity due to accumulation of abundant lipid peroxidation products like 4-Hydroxynonenal (HNE) and MDA (Awasthi et al., 2003b; Hossain and Fujita, 2010). Under saline stress upregulation of GST activities also reported by Hoque et al., (2007a) in tobacco, Rohman et al, (2009) in onion. Recently, Csiszár et al. (2011) reported the higher GST activities in tomato plant 
under salinity stress suggesting its stress tolerant. Csiszár et al. (2011) also reported that supplementation of salicylic acid enhance the activity under this saline condition.

Proline and betaine two major organic osmolytes that accumulate in a variety of plant species in response to environmental stresses such as drought, salinity, extreme temperatures, UV radiation and heavy metals. In this study, the foliar application of proline at 3 day, 5 day and 7 day stress of $4 \mathrm{dS} / \mathrm{m}, 8 \mathrm{dS} / \mathrm{m}, 12$ $\mathrm{dS} / \mathrm{m}$ and $16 \mathrm{dS} / \mathrm{m}$ salinity the GST activities increased over control and over $\mathrm{NaCl}$ treatment. Ketchum et al. (1991), Ober and Sharp (1994), Sharp et al. (1994) found the similar result. It may be due to drought or salinity stress in plants, proline accumulation normally occurs in the cytosol where it contributes substantially to the cytoplasmic osmotic adjustment. In addition to its role as an osmolyte for osmotic adjustment, proline contributes to stabilizing sub-cellular structures (e.g. membranes and proteins), scavenging free radicals, and buffering cellular redox potential under stress conditions, protein compatible hydrotrope (Srinivas and Balasubramanian, 1995), alleviating cytoplasmic acidosis, and maintaining appropriate NADP+/NADPH ratios compatible with metabolism (Hare and Cress, 1997). Furthermore, proline is known to induce expression of salt stress responsive genes, which possess proline responsive elements (e.g. PRE, ACTCAT) in their promoters (Satoh et al., 2002; Oono et al., 2003; Chinnusamy et al., 2005).

On the other hand, betaine also mitigates adverse effects of salinity stress in some plant species (Måkela et al., 1998a, b). In this study, the foliar application of betaine at 3 day, 5 day and 7 day stress of 4 $\mathrm{dS} / \mathrm{m}, 8 \mathrm{dS} / \mathrm{m}, 12 \mathrm{dS} / \mathrm{m}$ and $16 \mathrm{dS} / \mathrm{m}$ salinity the GST activities increased over control and over $\mathrm{NaCl}$ treatment; but only $8 \mathrm{dS} / \mathrm{m}$ salinity at 7 day stress, $12 \mathrm{dS} / \mathrm{m}$ at 3 day stress, $16 \mathrm{dS} / \mathrm{m}$ at 3 day stress it decreased the activity over $\mathrm{NaCl}$ treatment. Harinasut et al. (1996), Lutts (2000) found the similar result. In maize (Zea mays, L.), exogenously applied betaine improved growth, leaf water content, net photosynthesis, and the apparent quantum yield of photosynthesis of the salt-stressed plants (Yang and $\mathrm{Lu}, 2005$ ). Betaine application, however, did not affect maximum efficiency of PSII photochemistry. The improvement in photosynthesis of salt-stressed maize plants by betaine application was suggested to be associated with improvements in stomatal conductance and actual PSII efficiency. Betaine-treated plants had significantly lower $\mathrm{Na}+$ and higher $\mathrm{K}+$ concentrations in the shoots, compared with untreated plants. Furthermore, salt-induced ultrastructural damages to the leaf, including swelling of thylakoids, disintegration of grana stacking and intergranal lamellae, and destruction of mitochondria, were prevented by betaine pre-treatment These beneficiary effects in the shoot were suggested to be due to betaine-induced production of additional vacuoles in root cells, which resulted in a greater accumulation of $\mathrm{Na}+$ in the root and a decrease in its transportation to the shoot. In the root, the most frequently observed ultra-structural change due to salt stress was an increase in the number and aggregation of mitochondria in the cytoplasm of the root tip and root cap cells. But at higher concentration and at higher day's duration, the decreased GST activities might be due to loss of cellular membrane intrigity.

Both proline and betaine are reported to increase activities of antioxidant enzymes including GSTs (Hossain and Fujta, 2010; Hoque et al., 2008) through activation. In this study, the exogenous application of both proline and betaine also activated GST in maize seedlings (Fig 1-12). In combination of both proline and betaine treatment 3 day, 5 day and 7 day stress of $4 \mathrm{dS} / \mathrm{m}, 8 \mathrm{dS} / \mathrm{m}, 12 \mathrm{dS} / \mathrm{m}$ and $16 \mathrm{dS} / \mathrm{m}$ salinity the GST activities increased over control and over $\mathrm{NaCl}$ treatment; but only 3 day and 7 day stress of $4 \mathrm{dS} / \mathrm{m}$ salinity, 3 day stress of $8 \mathrm{dS} / \mathrm{m}$ and $12 \mathrm{dS} / \mathrm{m}$ salinity decreased the activity over $\mathrm{NaCl}$ treatment. This may be due to in from maintaining the cell membrane integrity and photosynthesis system. They might keep the concentration of $\mathrm{Na}^{+}$lower through creating vacuole.

Under abiotic stress production of that 4-Hydroxynonenal (HNE) and melondialdehyde (MDA) the major end products of lipid peroxidation which causes the membrane disruption (Awasthi et al., 2004; Hossain and Fujita, 2010).

\subsection{Changes in concentration of MDA in maize seedlings under salinity stress}

Since GSTs are reported to detoxify indigenous cytotoxic compounds under stress condition (Marrs 1996). Recently Csiszár et al. (2011) reported the detoxification role of GSTs in melondialdehide (MDA), the peroxidation product of polyunsaturated fatty acid. Therefore, in this study, the concentration of MDA in stressed maize seedlings to examine the detoxification role of maize GST. A linear increase was observed in the concentration of MDA in maize seedlings with duration of stress and concentration of salinity (Fig. 13). At 3 day stress, all of the salinity levels significantly increased the MDA contents, where, the concentration increased with the increasing salinity levels. At this level, content of MDA increased $31.53 \%, 37.77 \%, 39.74 \%$ and $45.40 \%$ over control at 4, 8, 12 and $16 \mathrm{dS} / \mathrm{m}$ salinity, respectively. This concentration further increased with duration. At 5 day stress, content of MDA increased 39.33\%, 49.57\%, 56.04\% and 59.28\% over control at 4, 8, 12 and $16 \mathrm{dS} / \mathrm{m}$ salinity, respectively, which further increased $59.90 \%, 63.05 \%, 73.02 \%$ and $77.27 \%$ over control at 4, 8, 12 and $16 \mathrm{dS} / \mathrm{m}$ salinity, respectively at seven day stress. Application proline and betaine were found to maintain the MDA concentration lower than the concentration at different salinity levels, though the concentrations were higher than the control (Fig. 13). Proline was found to reduce the MDA concentrations in 
most of the cases. However, at higher concentrations betaine performed better. At 3 day stress, proline caused $9.24 \%, 12.25 \%, 11.68 \%$ and $12.14 \%$ reduction in MDA contents over $4,8,12$ and $16 \mathrm{dS} / \mathrm{m}$ salinity, respectively, where, betaine caused $8.21 \%, 4.57 \%, 2.79 \%$ and $9.02 \%$ reduction and combination of proline and betaine caused $11.29 \%, 7.59 \%, 4.58 \%$ and $9.54 \%$ reduction. At 5 day stress, proline caused $14.50 \%, 18.94 \%$, $22.37 \%$ and $25.17 \%$ reduction in MDA contents over 4, 8, 12 and $16 \mathrm{ds} / \mathrm{m}$ salinity, respectively, where, betaine caused $10.23 \%, 10.78 \%, 13.93 \%$ and $19.43 \%$ reduction and combination of proline and betaine caused $11.25 \%$, $14.04 \%, 9.60 \%$ and $22.22 \%$ reduction. At 7 day stress, proline caused $20.05 \%, 24.91 \%, 22.80 \%$ and $19.84 \%$ reduction in MDA contents over 4, 8, 12 and $16 \mathrm{dS} / \mathrm{m}$ salinity respectively, where, betaine caused $15.41 \%$, $15.00 \%, 18.57 \%$ and $27.63 \%$ reduction and combination of proline and betaine caused $15.40 \%, 17.81 \%, 20.51 \%$ and $18.69 \%$ reduction.
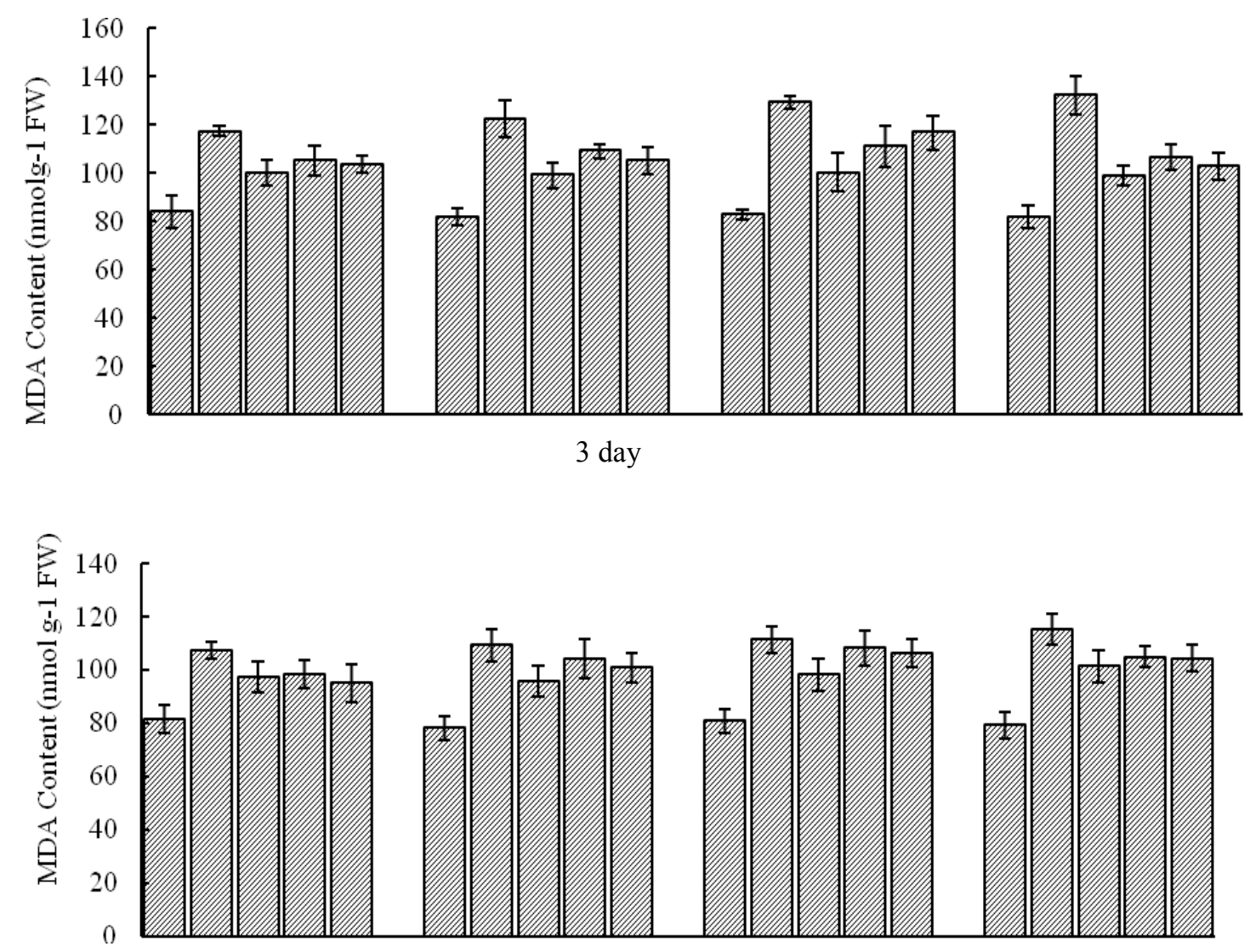

5 day

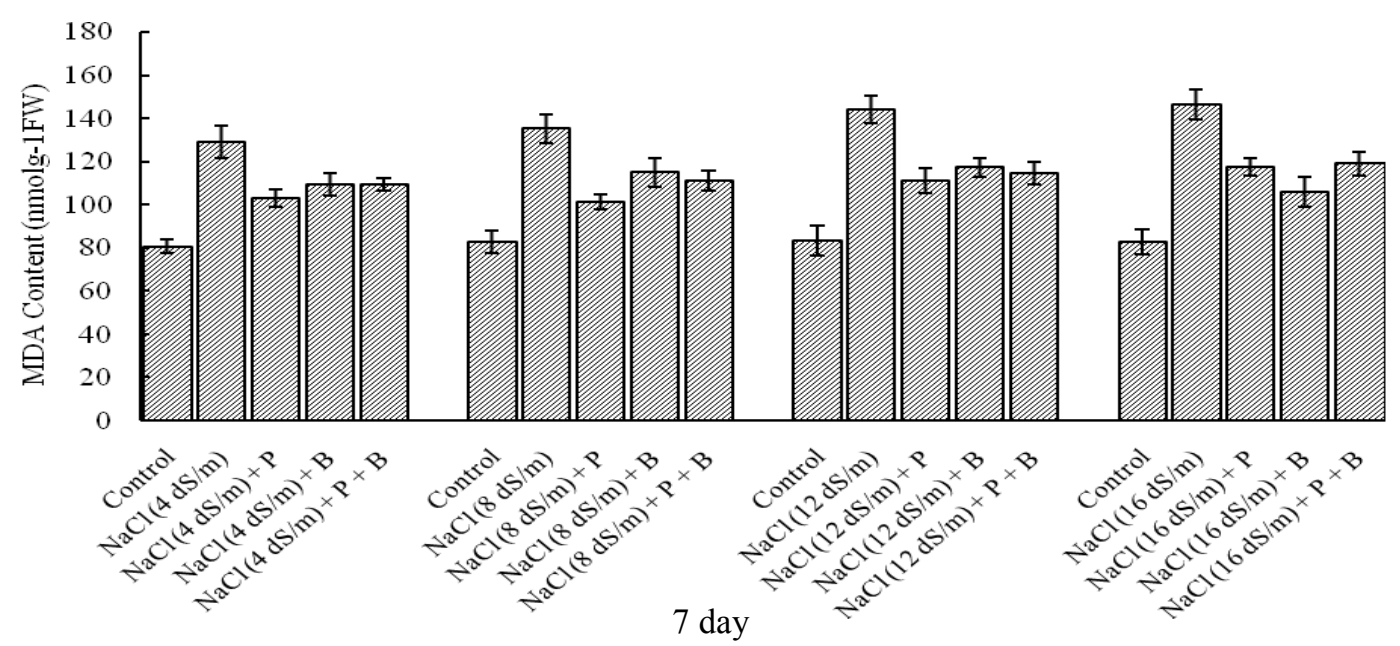

Fig. 13. Changes in MDA contents in maize seedlings under $\mathrm{NaCl}$ stress conditions supplemented with proline and betaine. 
Importantly, the reduction in concentrations of MDA under salinity stress with supplementation of proline and betaine had correlation with the expression of GST activities. The maximum reduction of MDA caused in the seedlings where the highest expression of GST was observed. The simultaneous increase in MDA contents and GST activities indicated important biological relation between them under salinity stress. Recently, increased GST activity along with decreased content of MDA under salinity supplement with glycine and betaine has been reported (Hossaain and Fujita, 2010; Hoque et al., 2008). In this study, the decreased contents of MDA (Fig. 13) with increased GST activities (Fig. 1-12) in proline and betaine supplemented maize seedlings under $\mathrm{NaCl}$ stress suggesting the detoxification role of GST. These detoxifications might maintain the lower concentration of MDA confer better membrane integrity and photosynthesis (Csiszár et al., 2011).

\section{Conclusion}

GST activities changes in different levels with duration of stress and concentration of salinity. GST activity were increased gradually over control at 3 day, 5 day stress at $4 \mathrm{dS} / \mathrm{m}, 8 \mathrm{dS} / \mathrm{m}, 12 \mathrm{dS} / \mathrm{m}$ salinity level, but incase of $16 \mathrm{dS} / \mathrm{m}$ salinity at 7 day stress GST activity was found down regulated over control. In foliar application of proline GST activity were increased gradually over control and $\mathrm{NaCl}$ treatment. In betaine treated seedlings at 3 day, 5 day and 7 day stress of $4 \mathrm{dS} / \mathrm{m}, 8 \mathrm{dS} / \mathrm{m}, 12 \mathrm{dS} / \mathrm{m}$ and $16 \mathrm{dS} / \mathrm{m}$ GST activity were increased gradually over control, but only $8 \mathrm{dS} / \mathrm{m}$ salinity at 7 day stress, $12 \mathrm{dS} / \mathrm{m}$ at 3 day stress, $16 \mathrm{dS} / \mathrm{m}$ at 3 day stress it were decreased the activity over $\mathrm{NaCl}$ treatment. In combination of both proline and betaine treatment GST activity were increased gradually over control and $\mathrm{NaCl}$ treatment only at 3 day and 7 day stress of $4 \mathrm{dS} / \mathrm{m}$ salinity, 3 day of $8 \mathrm{dS} / \mathrm{m}$ salinity and $12 \mathrm{dS} / \mathrm{m}$ salinity decreased activity. Lower concentration of MDA suggested the detoxification role of maize GST.

\section{References}

[1]. Abenavoli, M.R., D. Santis, C.M. Sidari, A. Sorgona, M. Badiani and G. Cacco. 2001. Influence of coumarin on the net nitrate uptake in durum wheat. New Phytologist. 150: 619-627.

[2]. Alexios, N., Polidoros and J. G. Scandalios. 1999. Role of hydrogen peroxide and different classes of antioxidants in the regulation of catalase and glutathione S-transferase gene expression in maize (Zea mays L.). Physiologia Plantarum. 106: 112-120.

[3]. Anderson, J.V. and D.G. Davis. 2004. Abiotic stress alters transcript profiles and activity of glutathione S-transferase, glutathione peroxidase, and glutathione reductase in Euphorbia esula. Physiol Plant. 120: 421-433.

[4]. Ashraf, M. and M. R. Foolad. 2007. Roles of glycine betaine and proline in improving plant abiotic stress resistance. Environ Exp Bot. 59:206-216.

[5]. Atkins, W.M., W. Regina, W. Andrew and Y. H. Anthony. 2003. The catalytic mechanism of glutathione S-transferase (GSTs). The Journal of Biological Chemistry. . 26: 267-268.

[6]. Awasthi, Y.C., Y.Yang, N.K. Tiwari and S. Awasthi. 2004. Regulation of 4-hydroxynonenal-mediated signaling by gluathione Stransferases. Free Radical Biology and Medicine. 27(5): 607-619.

[7]. Awasthi. S., S.S. Singhal, J. Singhal, Y. Yang, P. Zimniak, Y.C. Awasthi. 2003b. Role of RLIP76 in lung cancer doxorubicin resistance: III. Anti-RLIP76 antibodies trigger apoptosis in lung cancer cells and synergistically increase doxorubicin cytotoxicity. Acta Biologica Szegediensis. 56(1):69-70.

[8]. Blokhina, O., E. Virolainen and K.V. Gagerstedt. 2003. Antioxidants, oxidative damage and oxygen deprivation stress: a review. Ann Bot (Lond). 91: 179-194.

[9]. Chinnusamy, V., A. Jagendorf and J. Zhu. 2005. Understanding and improving salt tolerance in plants. Crop Sci. 45:437-448.

[10]. Csiszár, J., Z. Váry, E. Horváth, A. Gallé and I. Tari. 2011. Role of glutathione transferases in the improved acclimation to salt stress in salicylic acid-hardened tomato. Acta Biologica Szegediensis. 55(1):67-68.

[11]. Dean, J.D., P.H. Goodwin and T. Hsiang. 2005. Induction of glutathione S-transferase genes of Nicotiana benthamiana following infection by Colletotrichum destructivum and C. orbiculare and involvement of one in resistance. J. Exp. Bot. 56: 1525-1533.

[12]. Dixon, E.T., R. Mornet and M. Laloue. 2002. Mechanism of action of glutathione-dependent enzymes. Adv. Enzymol. Relat. Areas Mol. Biol. 59: 103-67.

[13]. Hare, P.D. and W.A. Cress. 1997. Metabolic implications of stress-induced proline accumulation in plants. Plant Growth Regul. 21: $79-102$.

[14]. Harinasut, P., K. Tsutsui, T. Takabe, M. Nomura and S. Kishitani. 1996. Exogenous glycine betaine accumulation and increased salt tolerance in rice seedlings. Biosci. Biotechnol. Biochem. 60, 366-368.

[15]. Hoque, M.A., M.N.A. Banu, E. Okuma, K. Amako, Y. Nakamura and Y. Murata 2007a Exogenous proline and glycinebetaine increase $\mathrm{NaCl}$-induced ascorbate-glutathione cycle enzyme activities, and proline improves salt tolerance more than glycinebetaine in tobacco Bright Yellow-2 suspension-cultured cells. J Plant Physiol. 164: 1457-1468.

[16]. Hossain, M.A and M. Fujita. 2010. Evidence for a role of exogenous glycinebetaine and proline inantioxidant defense and methylglyoxal detoxification systems in mung bean seedlings under salt stress. Physiol. Mol. Biol. Plants. 16(1) : 19-29.

[17]. Jepson, I., V.J. Lay, D.C. Holt, S.W.J. Bright and A. J. Greenland. 1994. Cloning and characterization of maize herbicide safenerinduced cDNAs encoding subunits of glutathione-S-transferase isoform-I, isoform-II and isoform-IV. Plant Molecular Biology. 26, 1855-1866.

[18]. Ketchum, R.E.B., R.C. Warren, L.J. Klima, F. Lopez-Gutierrez, M.W. Nabors. 1991. The mechanism and regulation of proline accumulation in suspensioncultures of the halophytic grass Distichlis spicata L. J. Plant Physiol. 137:368-374.

[19]. Lutts, S. 2000. Exogenous glycine betaine reduces sodium accumulation in salt-stressed rice plants. Int. Rice Res. Notes 25:39-40.

[20]. $\mathrm{M}^{\circ}$ akela, P., K. Jokinen, M. Kontturi, S. Somersalo, 1998a. Foliar application of glycine betaine - a novel product from sugarbeetas an approach to increase tomato yield. Ind. Crops Prod. 7: 139-148.

[21]. $\mathrm{M}^{\circ}$ akela, P., P. Peltonen-Sainio, K. Jokinen, E. Pehu and H. Setala. 1998b. Effect of foliar application of glycine betaine on stomatal conductance, abscisic acid and solute concentrations in leaves of salt- and drought-stressed tomato. Aust. J. Plant Physiol. 25:655-663. 
[22]. Marrs, K.A. 1996. Functions and regulation of glutathione S-transferases in plants. Annu. Rev. Plant Physiol. Plant Mol. Biol., 47: 127-158.

[23]. Mueller, L.A., C.D. Goodman, R. A. Silady and V. Walbot. 2000. A petunia glutathione S-transferase required for anthocyanin sequestration, is a flavonoid-binding protein. Plant Physiol. 123: 1561-1570.

[24]. Ober, E.S. and R.E. Sharp. 1994. Proline accumulation in maize (Zea mays L.) primary roots at low water potentials. I. Requirement for increased levels of abscisic acid. Plant Physiol. 105: 981-987.

[25]. Oono, Y., C. Ooura, A. Rahman, E.T. Aspuria and H. Uchimiya. 2003. p-clorophenoxyisobutyric acid impairs auxin response in Arabidopsis root. Plant Physiol. 133:1135-1147.

[26]. Rohman, M.M., M.D. Hossain, T. Suzuki. G. Takada, and Fujita, M. 2009. Quercetin-4'-glucoside: a physiological inhibitor of the activities of dominant glutathione S- transferases in onion (Allium cepa L.) bulb. Acta Physiol Plant. 31: 301-309.

[27]. Satoh, R., K., M. Nakashima and K. Shinozaki. 2002. A novel cis-acting element for proline- and hypoosmolarity-responsive expression of the ProDH gene encoding proline dehydrogenase in Arabidopsis. Plant Physiol.130: 709-719.

[28]. Sharp, R.E., Y. Wu., G.S. Voetberg and I.N. Saab. 1994. Confirmation that abscisic acid accumulation is required for maize primary root elongation at low water potentials. J. Exp. Bot. 45: 1717-1743.

[29]. Srinivas, V. and D. Balasubramanian. 1995. Proline is a protein-compatible hydrotrope. Plant Physiol. 11: $2830-2833$.

[30]. Wang, L.P., Y.X. Zhao and H. Zhang. 2002. Cloning and sequencing of GST gene of Suaeda salsa and its expression characteristics. J. Plant Physiol. Mol. Biol. 28: 133-136.

[31]. Yang, X. and C. Lu. 2005. Photosynthesis is improved by exogenous glycinebetaine in salt-stressed maize plants. Physiol. Plant. 124, 343-352.

[32]. Yang, Y., J. Cheng, S.S. Singhal, M. Saini, U. Pandya, S. Awasthi and Y.C. Awasthi. 2001. Role of Glutathione S-transferase in protection against lipid peroxidation. J. Biol. Chem. 276: 19220-19230.

[33]. Yang. Y., J. Cheng, S.S. Singhal, M. Saini, U. Pandya, S. Awasthi and Y.C. Awasthi. 2003. Studied on role of glutathione Stransferases in the regulation of lipid hydroperoxide levels reaffirm that GSTs play a key role in regulating lipid peroxidation by terminating the autocatalytic chain of lipid peroxidation. Int J Oncol. 21: 741-742. 